\title{
DUAS DÉCADAS DA PNEA: AVANÇOS E RETROCESSOS NO BRASIL
}

\author{
Maria Angélica Garcia ${ }^{1}$ \\ Izabel Cristina Bruno Bacelar Zaneti ${ }^{2}$ \\ Silvia Machado Yonamine ${ }^{3}$ \\ Andreia Pereira Silverio ${ }^{4}$ \\ Érika Nazaré Gadelha Meira Cerqueira ${ }^{5}$ \\ Maria Grazielle Lobato Silva ${ }^{6}$
}

Resumo: Este artigo apresenta os principais avanços, assim como os retrocessos técnicos e político-institucionais nas duas décadas de vigência da Política Nacional de Educação Ambiental - PNEA. Para tanto, foi feita pesquisa intensiva na ferramenta Google Acadêmico, em artigos, teses, dissertações e em outras publicações sobre Educação Ambiental e sobre suas políticas públicas, desenvolvidas entre 1999 e 2019. Observou-se uma tendência crescente de publicações com esse conteúdo no período $\left(r^{2}=0,9594\right)$ de 1999 a 2019, mas um forte declínio em 2019. Todavia, preveem-se mudanças significativas nos planos, programas e projetos desenvolvidos pelo MMA e pelo MEC, seus órgãos gestores, devido às mudanças político-administrativas em desenvolvimento pelo governo federal (2019-2022).

Palavras-chaves: Educação Ambiental; PNEA; sustentabilidade.

Abstract: This article presents the main technical and political-institutional advances and setbacks in the two decades of the National Environmental Education Policy of Brazil - PNEA (Federal Law no9.785/1999). Intensive research was carried out on the Google Scholar tool, articles, theses, dissertations and other publications that concerns Environmental Education and public policies developed between 1999 and 2019. There was an increasing trend in publications in the period $\left(r^{2}=0.9559\right)$ from 1999 to 2019 , with a small decline in 2019. However, significant changes are foreseen in the plans, programs and projects developed by its management group (MMA and MEC) in view of the changes promoted in the current Federal Government (2019-2022).

Keywords: Environmental Education; PNEA; Sustainability.

\footnotetext{
1 Universidade de Brasília. biol.mariagarcia@gmail.com. http://lattes.cnpq.br/8195358691195578

2 Universidade de Brasília. izabel.zaneti@yahoo.com. http://lattes.cnpq.br/6400809887186849

3 Universidade de Brasília. silvia.yonamine@gmail.com. http://lattes.cnpq.br/9259836046014810

4 Universidade de Brasília. andreia_psilverio@hotmail.com. http://lattes.cnpq.br/4054585901219007

5 Universidade de Brasília. erikagadelha234@hotmail.com. http://lattes.cnpq.br/9484432845529360

6 Universidade de Brasília. grazilobato@hotmail.com. http://lattes.cnpq.br/5208280712216950
} 


\section{Introdução}

A Política Nacional de Educação Ambiental - PNEA promulgada por meio da Lei no 9.785, em 27 de junho de 1999, completou duas décadas de vigência e exigiu um crescente esforço dos diversos segmentos da sociedade, tanto governamentais, quanto não governamentais, para sua efetivação.

Ao considerar a PNEA como política pública, ou seja, como programa ou diretriz para solucionar um problema que aflige a sociedade, pode-se observar sua trajetória desde a identificação do problema, a análise e a solução. O processo de criação de uma política pública é definido como Ciclo da Política Pública (policy cycle), conforme Secchi (2014).

De acordo com diferentes autores, esse ciclo possui diversas etapas. Souza (2006) apresenta as seguintes: definição de agenda, identificação de alternativas, avaliação das opções, seleção das opções, execução e avaliação. Considera, ainda, que a identificação do problema deve preceder à definição da agenda.

Historicamente, antes de se iniciar qualquer debate sobre a adoção de uma política de Educação Ambiental (EA) no Brasil, o tema já era considerado, internacionalmente, como um imprescindível instrumento de sensibilização para práticas ambientais mais sustentáveis.

Tal debate se iniciou na Conferência Mundial sobre o Meio Ambiente e Desenvolvimento, (Conferência de Estocolmo das Nações Unidas sobre o Meio Ambiente), em 1972. Em 1977, houve a Conferência Intergovernamental sobre Educação Ambiental, em Tbilisi (Geórgia). Esses e outros eventos internacionais foram propulsores das discussões de Educação Ambiental (EA) e resultaram no Tratado de Educação Ambiental para Sociedades Sustentáveis e Responsabilidade Global, elaborado em 1992, quando da Conferência das Nações Unidas sobre Meio Ambiente e Desenvolvimento-Cnumad - a Rio 92.

No Brasil, os avanços das temáticas de meio ambiente e de EA emergem do arcabouço legal marcado pela promulgação da Lei Federal no 6.938, em 31 de agosto de 1981, por meio da qual o governo brasileiro estabelece a Política Nacional do Meio Ambiente-PNMA e impõe, como princípio, a "Educação Ambiental em todos os níveis de ensino e a conscientização para a preservação do meio ambiente" (BRASIL, 1981).

Depois da redemocratização, a Constituição Federal de 1988 determina ao poder público promover "Educação Ambiental em todos os níveis de ensino e a conscientização para a preservação do meio ambiente" (BRASIL, 1988).

A partir dos compromissos emanados da Rio-92 e baseados nos princípios estabelecidos na referida Conferência de Estocolmo, promulga-se, no Brasil, a PNEA, por meio da Lei Federal no 9.795, em 27 de junho de 1999. 
A PNEA estabelece diretrizes para o ensino de Educação Ambiental $(E A)$, tendo em vista que, até aquele momento, não havia legislação específica sobre o tema, tampouco ações de incentivo e de promoção.

Em 25 de junho de 2002, é promulgado o Decreto $\mathrm{n}-4.281$, que regulamentou a PNEA e indicou o Ministério de Meio Ambiente - MMA e o Ministério da Educação - MEC como seus órgãos gestores (OG) da EA.

Decorridas duas décadas, necessário se faz um olhar sobre os avanços, desde a promulgação da PNEA, em termos de planos, programas e projetos públicos e privados desenvolvidos no Brasil. Outrossim, diante da situação político-institucional atual, o objetivo deste artigo é relatar os avanços obtidos e os retrocessos que se vislumbram.

\section{Metodologia}

Para a pesquisa aqui desenvolvida assumiu-se a teoria de Castells (2008), segundo a qual a sociedade contemporânea experimenta a Era da Informação, época em que os avanços tecnológicos determinam uma nova dinâmica econômico-social mundial e habilitam todos os conectados na Rede Mundial de Computadores - Internet o acesso a informações e a novas tecnologias.

Assim, lançar mão de dados webométricos para explicar a permeabilização e a transversalidade do tema da Educação Ambiental, a partir da promulgação da PNEA, é uma estratégia metodológica válida, pois a Internet permite acesso livre ao que acontece no mundo.

O método adotado para identificar a relação 'políticas públicas versus evolução da prática de EA no Brasil' foi o de catalogar as publicações técnicocientíficas - artigos, livros, relatórios - existentes na Internet, sobre o tema.

Para tanto, adotaram-se conceitos webométricos, pois toda a coleta de dados foi feita no Google Acadêmico - GA, extraindo-se dali os documentos indexados que se referem, explicitamente, à Educação Ambiental - EA, em idioma português (Brasil) fosse no título ou no corpo do artigo.

De acordo com Spinak (2019), o GA tem, consistentemente, o maior percentual de citações em todas as áreas $(93 \%-96 \%)$, bem à frente do Scopus $(35 \%-77 \%)$ e do WoS $(27 \%-73 \%)$. O GA encontrou quase todas as citações do WoS (95\%) e do Scopus (92\%).

O período examinado foi de 1999 a 2019, compreendendo as duas décadas de vigência da PNEA. Além disso, consideraram-se somente artigos, livros, legislação e outras publicações indexadas no GA, sendo desconsiderados vídeos, matérias jornalísticas ou outros não submetidos a um conselho editorial de periódicos científicos ou bancas examinadoras.

A identificação das políticas públicas afetas ao objetivo do artigo se restringiu àquelas promovidas pelo MMA e pelo MEC, órgãos gestores, 
desconsiderando-se políticas ou programas de governo nos níveis estaduais e municipais.

A Constituição Federal da República Federativa do Brasil determina que as ações de EA sejam desenvolvidas pelos Estados, Distrito Federal e municípios, em consonância com o que determina a União. Assim foram realizadas intensiva pesquisa nos sítios eletrônicos dos ministérios envolvidos e, também, pesquisa webométrica sobre tais ações.

\section{Resultados e Discussão}

\section{Evolução Quantitativa das Publicações em EA no Brasil}

Assumindo que a produção técnico-científica é um bom indicador de desempenho para avaliar a repercussão da PNEA como indutor de divulgação de experiências e lições aprendidas em EA, analisou-se a tendência de publicações ao longo dos seus vinte anos de vigência. De acordo com os dados levantados no GA, houve uma crescente evolução de publicações técnico-científicas relacionadas ao tema da Educação Ambiental.

Os totais apresentados na Tabela 1 referem-se às publicações indexadas no GA, com a expressão 'Educação Ambiental' em qualquer parte do corpo do texto publicado no período entre 1999 a 2019.

Tabela 1: Número total de publicações indexadas no GA com a expressão "Educação Ambiental" presente em qualquer parte dos artigos indexados no GA - 1999 a 2019.

\begin{tabular}{ccc|ccc}
\hline Ano & Anual & Cumulativo & Ano & Anual & Cumulativo \\
\hline 1999 & 705 & 705 & 2010 & 7.610 & 42.047 \\
2000 & 992 & 1.697 & 2011 & 9.100 & 51.147 \\
2001 & 1.200 & 2.897 & 2012 & 9.350 & 60.497 \\
2002 & 1.700 & 4.597 & 2013 & 10.300 & 70.797 \\
2003 & 2.260 & 6.857 & 2014 & 11.600 & 82.397 \\
2004 & 2.660 & 9.517 & 2015 & 13.400 & 95.797 \\
2005 & 3.290 & 12.807 & 2016 & 13.700 & 109.497 \\
2006 & 4.160 & 16.967 & 2017 & 13.400 & 122.897 \\
2007 & 4.840 & 21.807 & 2018 & 13.800 & 136.697 \\
2008 & 5.200 & 27.007 & 2019 & 12.000 & 148.697 \\
2009 & 7.430 & 34.437 & & \\
\hline \multicolumn{7}{c}{148.697} \\
\hline
\end{tabular}

Fonte: Autoria própria (2020).

Na Figura 1, é apresentada a evolução quantitativa das consultas ao GA, as quais demonstraram número crescente de produções técnico-científicas relacionadas à Educação Ambiental, tendo o termo sido citado no artigo ou na publicação. Quanto à presença da expressão EA, no título, a diferença quantitativa de publicações é significativamente menor, como se depreende da análise da Tabela 2. 


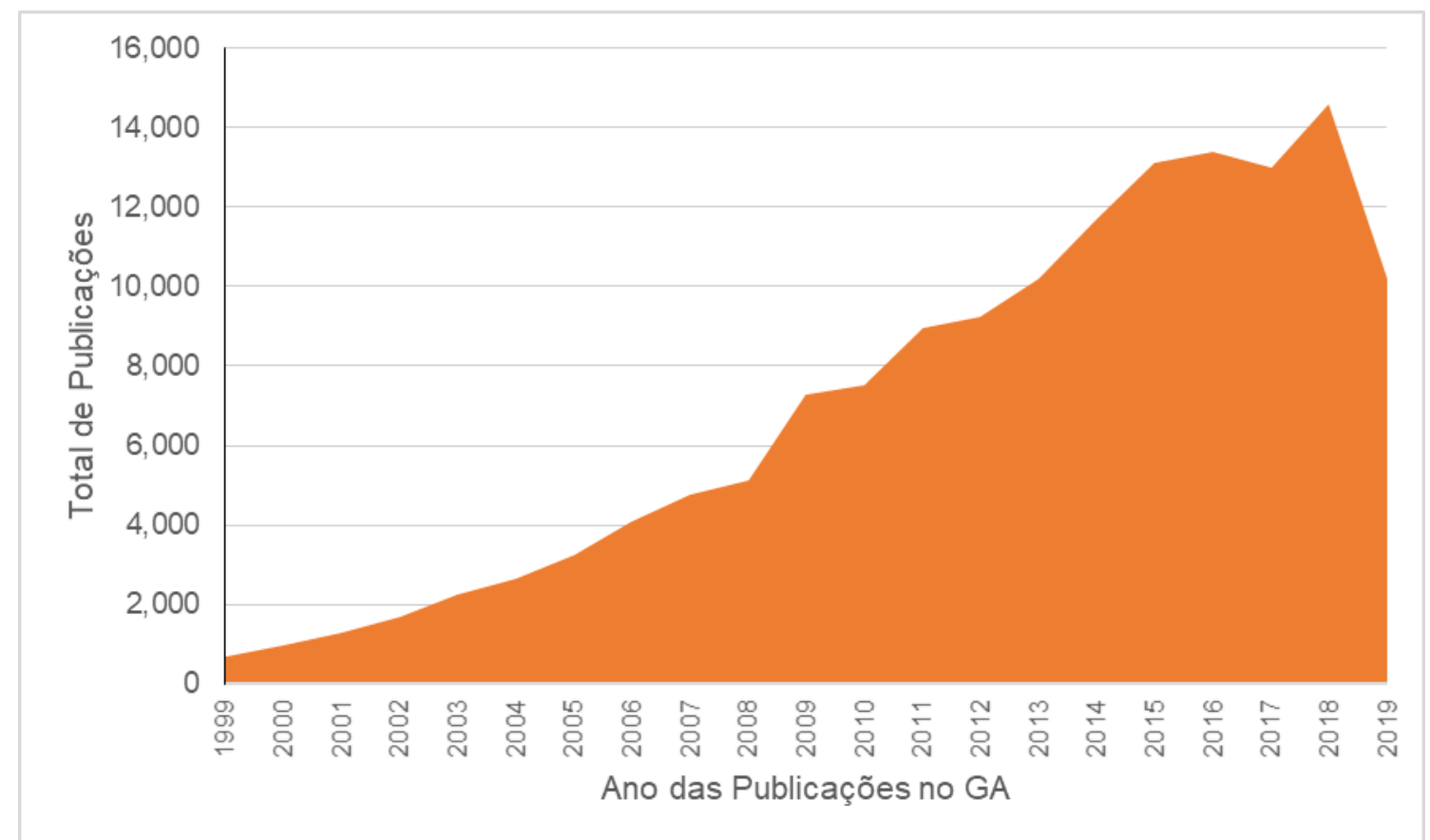

Figura 1: Evolução Quantitativa de Publicações de EA no período 1999-2019.

Fonte: Autoria própria (2020).

Tabela 2: Número total de publicações indexadas no GA com a expressão 'Educação Ambiental' apenas no título dos artigos indexados no GA - período 1999 a 2019.

\begin{tabular}{lc|ll}
\hline Ano & Total & Ano & Total \\
\hline $\mathbf{1 9 9 9}$ & 163 & $\mathbf{2 0 1 0}$ & 1.050 \\
$\mathbf{2 0 0 0}$ & 295 & $\mathbf{2 0 1 1}$ & 1.110 \\
$\mathbf{2 0 0 1}$ & 362 & $\mathbf{2 0 1 2}$ & 1.180 \\
$\mathbf{2 0 0 2}$ & 400 & $\mathbf{2 0 1 3}$ & 1.200 \\
$\mathbf{2 0 0 3}$ & 435 & $\mathbf{2 0 1 4}$ & 1.220 \\
$\mathbf{2 0 0 4}$ & 479 & $\mathbf{2 0 1 5}$ & 1.530 \\
$\mathbf{2 0 0 5}$ & 594 & $\mathbf{2 0 1 6}$ & 1.380 \\
$\mathbf{2 0 0 6}$ & 673 & $\mathbf{2 0 1 7}$ & 1.460 \\
$\mathbf{2 0 0 7}$ & 762 & $\mathbf{2 0 1 8}$ & 1.450 \\
$\mathbf{2 0 0 8}$ & 725 & $\mathbf{2 0 1 9}$ & 1.110 \\
$\mathbf{2 0 0 9}$ & 1.140 & & \\
\hline Total & & & \\
\hline
\end{tabular}

Fonte: Autoria própria (2020)

$\mathrm{Na}$ Figura 2, apresenta-se a curva de tendência ao longo dos anos em termos de incremento de produção técnico-científica. Entretanto, constata-se em 2017 e em 2019 incrementos menores do que os restantes do período analisado. Esse decréscimo pode ser explicado pela redução de incentivos e fomentos públicos para ações de EA no âmbito dos órgãos gestores, como se verá a seguir no item 0 . Até o momento, no geral, foi observada uma tendência de crescimento positiva (com um coeficiente de correlação linear $-r^{2}=0,9594$ ) ao longo do período em análise. 


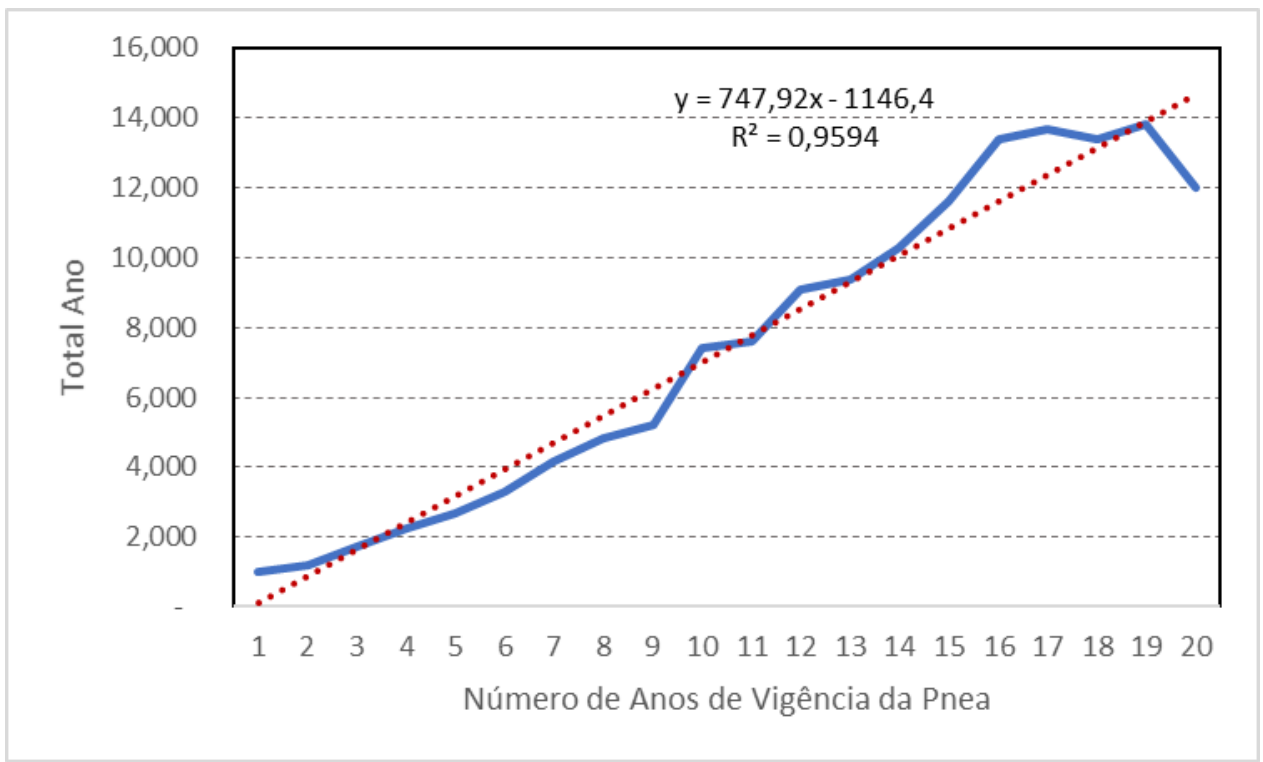

Figura 2: Tendência de crescimento da tratativa do tema EA nos vinte anos da PNEA no Brasil.

Todavia, essa ruptura da tendência positiva de crescimento, estagnado em 2016 e reduzido em 2019, já provoca divergências entre o governo central e ambientalistas e educadores que dependem, mormente, das políticas e incentivos públicos até então executados sob a égide dos ditames legais e constitucionais.

\section{Planos e Programas relacionados à PNEA}

Segundo o disposto no artigo 3o, inciso I da PNEA (BRASIL, 1999, op. cit.), ao poder público compete, 'definir as políticas públicas que incorporem a dimensão ambiental, promover a EA em todos os níveis de ensino e o engajamento da sociedade na conservação, recuperação e melhoria do meio ambiente'.

A PNEA determina que as ações em EA sejam integradas à educação em geral e à educação escolar formal, conforme disposto em seu art. $8^{\circ}$ : a) capacitação de recursos humanos; b) desenvolvimento de estudos, produção e divulgação de material educativo e; c) acompanhamento e avaliação.

Tanto os programas quanto as ações concernentes à EA no âmbito do governo federal eram, até 2018, concentrados nos Ministérios do Meio Ambiente e da Educação. Ao MMA coube as políticas públicas de EA no âmbito da educação não formal e, ao MEC, as ações relacionadas à educação formal.

Conforme já exposto, as bases para a execução da PNEA foram regulamentadas somente em 2002, por meio do Decreto $\mathrm{n}$ ㅇ 4.281. A partir dele, 
foi instituído um Grupo de Trabalho de Educação Ambiental, formado pelos órgãos gestores da PNEA. Dentre as ações promovidas pelo Grupo, merece destaque a realização da I Conferência Infanto-Juvenil pelo Meio AmbienteCnijma (BRASIL, 2005).

A I Cnijma teve como objetivo discutir e propor ações e projetos relacionados à temática socioambiental, seus desafios e alternativas, do âmbito da escola até o âmbito global. O evento apresentou outras edições nacionais nos anos de 2003, 2005, 2006, 2009, 2013 e 2018 (MORAIS; VIEIRA; MORTELLA, 2018), nos quais participaram mais de quatro milhões de pessoas.

Em 2010, foi realizada sua edição internacional, a Conferência Internacional Infanto-Juvenil - Confint, intitulada "Vamos Cuidar do Planeta", que envolveu 62 países (BRASIL, 2018a).

Como resultado da I Cnijma, surgiu o "Movimento Coletivos Jovens de Meio Ambiente", um movimento horizontal e de autogestão direcionado a jovens de quinze a 29 anos, que contribuiu para incluir temas socioambientais na pauta de colegiados e movimentos de juventude (BARBOSA, 2008). Outro produto da I Cnijma foi o "Programa Nacional de Formação e Capacitação de Gestores Ambientais - PNC" do MMA.

O programa com maior destaque dentre as ações de EA do governo federal é o Programa Nacional de Educação Ambiental - Pronea, criado em 1994, gestado antes da promulgação da PNEA. Com a institucionalização da PNEA, o Pronea passou por uma grande reestruturação.

Sua segunda edição foi lançada em 2004 e reuniu mais de oitocentos gestores ambientais a partir de um procedimento democrático de discussão e interlocução entre o MEC e o MMA e, destes, com universidades e organizações da sociedade civil.

O Pronea sinalizou um novo "Patamar de compreensão do processo educativo" e estabeleceu as diretrizes para a EA no Brasil, quais sejam: a) transversalidade e interdisciplinaridade; b) descentralização espacial e institucional; c) sustentabilidade socioambiental; d) democracia e participação social e; e) aperfeiçoamento e fortalecimento de sistemas de ensino, meio ambiente e outros relacionados com a Educação Ambiental (LOUREIRO, 2004).

O Pronea, que continua sendo a principal referência de planejamento e execução de ações da PNEA, está em sua 5a edição, consolidada em 2018 (BRASIL, 2018b) e referendada no IX Fórum Brasileiro de Educação Ambiental, realizado em 2017. Como estratégia, propõe a adoção de três linhas de ação principais, cada uma com objetivo próprio (Figura 3). 


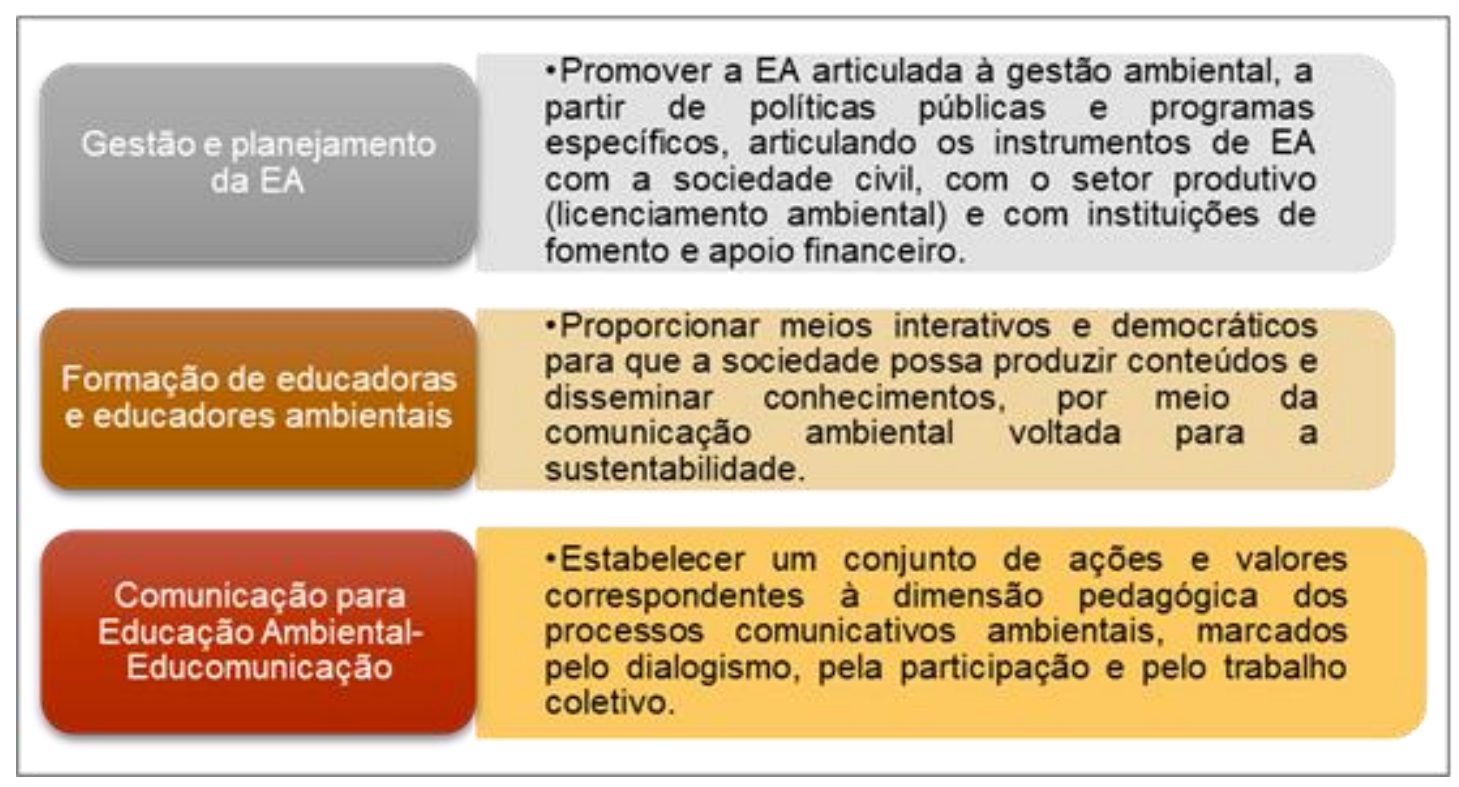

Figura 3: Linhas de Ação de Educação Ambiental segundo o Pronea (BRASIL, 2018b).

Nessas últimas duas décadas, foram propostos vários planos, programas e projetos vinculados à EA e à educação de qualidade na linha de ação de Formação de Educadores/Pronea, quais sejam:

- Programa Coletivos Educadores, no quadriênio 2003 - 2008: foram lançados editais de financiamento do programa em alguns Estados, para a execução de projetos estruturantes de uma EA permanente e continuada para todos os brasileiros e brasileiras (BRASIL, 2007);

- Programa Vamos Cuidar do Brasil (MEC, MMA e Unesco), iniciado em 2004 e reinserido do quadriênio PPA 2008-2011, consolidado pela Unesco (2007);

- Projeto "O que fazem as escolas que dizem que fazem Educação Ambiental?", uma iniciativa da Unesco, em parceria com o MEC e o MMA (TRAJBER; MENDONÇA, 2007), cuja pesquisa demonstrou a universalização da EA nas escolas, apontando que $61,2 \%$ das escolas trabalhavam com EA em 2001 e, em, 2004, esse percentual subiu para 95\%;

- Programa Nacional de Formação e Capacitação de Gestores Ambientais- PNC, instituído por meio da Portaria MMA no 286, em 2005, por demanda da Conferência Nacional de Meio Ambiente, para atender aos anseios de Estados e municípios, como uma estratégia de fortalecimento do Sistema Nacional do Meio Ambiente - Sisnama e de qualificação da gestão ambiental, a fim de capacitar gestores, servidores, técnicos ambientais e outros atores sociais, para colaborar com a estruturação de políticas no contexto federativo, envolvendo a 
responsabilização e o empoderamento dos entes nas três esferas de governo;

- Estratégia Nacional de Comunicação e Educação Ambiental-Encea no Sistema Nacional de Unidades de Conservação da Natureza-Snuc, pautada no Plano Estratégico Nacional de Areas Protegidas-Pnap, promulgado por meio do Decreto no 5.758 , de 13 de abril de 2006, voltada para o (re)conhecimento, a valorização, a criação, a execução, a gestão e a defesa das unidades de conservação, por todos e para todos.

- Programa de Educação Ambiental e Mobilização Social em Saneamento- PEAMSS, também estabelecido pelo MMA, com ações de formação de cidadãos comprometidos com a construção de "sociedades sustentáveis" (2009) entre outros.

O MMA, na linha de atuação da Educomunicação no Pronea, desenvolveu, até 2018, diversos projetos (Quadro 1).

A fim de permitir uma análise da atuação do poder público, relativamente aos mandados constitucionais e legais, referentes à execução da PNEA, são listadas as linhas orçamentárias incluídas nos Planos Plurianuais-PPAs, por quadriênio, (Quadro 2), bem como os principais projetos e programas entre 1999 a 2019, executados por seus órgãos gestores, o MEC e o MMA (Quadro $3)$.

Quadro 1: Lista de Projetos/Programas Desenvolvidos no Âmbito da Educomunicação Comunicação para a EA no Âmbito do Pronea.

\begin{tabular}{|c|l|}
\hline $\begin{array}{c}\text { Ano de } \\
\text { Execução }\end{array}$ & \multicolumn{1}{c|}{ Projetos/Programas/Agendas Temáticas } \\
\hline $2000-2020$ & Projeto Salas Verdes - último edital 2017 - 640 salas verdes cadastradas. \\
\hline 2008 & $\begin{array}{l}\text { Plataforma Coleciona - Fichário d@ Educador Ambiental - última edição em } \\
2018 \text { (15a). }\end{array}$ \\
\hline 2009 & $\begin{array}{l}\text { Projeto: Circuito Tela Verde (CTV) - sete edições, totalizando 322 vídeos } \\
\text { relacionados à temática socioambiental, alcançando 8.734 espaços } \\
\text { exibidores. }\end{array}$ \\
\hline 2009 & $\begin{array}{l}\text { Projeto "Nas Ondas do São Francisco" - produção de spots de rádio, que } \\
\text { foram veiculados em mais de 150 rádios na região do São Francisco. }\end{array}$ \\
\hline 2009 & $\begin{array}{l}\text { Programa Nacional de Apoio à Inclusão Digital nas Comunidades - Apoio a } \\
\text { Telecentros em áreas protegidas (unidades de conservação, terras indígenas } \\
\text { e comunidades tradicionais). }\end{array}$ \\
\hline 2014 & Projeto Educares - Política Nacional de Resíduos Sólidos. \\
\hline $2014-2018$ & $\begin{array}{l}\text { Concurso de Redação da Copa Verde com o tema desta 5a edição: } \\
\text { Programa "Vamos Cuidar do Brasil, Cuidando das Águas". }\end{array}$ \\
\hline
\end{tabular}

Fonte: Autoria própria (2020). 
Quadro 2: Programas, Objetivos e Ações Orçamentárias dos PPAs Voltados para a Temática de EA no Brasil.

\begin{tabular}{|c|c|c|c|}
\hline Ato & Programa & $\begin{array}{c}\text { Objetivo relacionado ao } \\
\text { Programa }\end{array}$ & Ação \\
\hline \multicolumn{4}{|c|}{$1996-1999$} \\
\hline $\begin{array}{l}\text { Lei no } 9.276 \text {, } \\
\text { de } 9 \text { de maio } \\
\text { de } 1996 .\end{array}$ & Meio Ambiente & $\begin{array}{c}\text { Promoção da EA pela } \\
\text { divulgação e pelo uso de } \\
\text { conhecimento sobre } \\
\text { tecnologias de gestão } \\
\text { sustentável dos recursos } \\
\text { naturais. }\end{array}$ & $\begin{array}{l}\text { Sem ação orçamentária } \\
\text { específica no PPA }\end{array}$ \\
\hline \multicolumn{4}{|c|}{$2000-2003$} \\
\hline \multirow{9}{*}{$\begin{array}{l}\text { Lei no } 9.989 \text {, } \\
\text { de } 21 \text { de } \\
\text { julho de } \\
2000 .\end{array}$} & \multirow{7}{*}{$\begin{array}{c}\text { Educação } \\
\text { Ambiental } \\
\text { (MMA) }\end{array}$} & \multirow{7}{*}{$\begin{array}{c}\text { Promover a } \\
\text { conscientização e a } \\
\text { capacitação da coletividade } \\
\text { na prevenção e na solução } \\
\text { dos problemas ambientais. }\end{array}$} & $\begin{array}{l}\text { a) Fomento a projetos } \\
\text { integrados de } E A \text {; }\end{array}$ \\
\hline & & & $\begin{array}{l}\text { b) efetivação de Sistema } \\
\text { Nacional de Informação em EA; }\end{array}$ \\
\hline & & & $\begin{array}{l}\text { c) informações e divulgação } \\
\text { técnico-científica (IPJB-RJ); }\end{array}$ \\
\hline & & & $\begin{array}{l}\text { d) capacitação de recursos } \\
\text { humanos em EA no processo de } \\
\text { gestão do meio ambiente; }\end{array}$ \\
\hline & & & $\begin{array}{l}\text { e) edição e distribuição de } \\
\text { informações técnico-científicas; }\end{array}$ \\
\hline & & & $\begin{array}{l}\text { f) criação de polos de difusão de } \\
\text { práticas sustentáveis; }\end{array}$ \\
\hline & & & $\begin{array}{l}\text { g) educação do produtor rural } \\
\text { para o uso de práticas } \\
\text { conservacionistas (BB - Agenda } \\
\text { Verde). }\end{array}$ \\
\hline & $\begin{array}{l}\text { Águas do Brasil } \\
\text { (MMA) }\end{array}$ & $\begin{array}{c}\text { Contribuir para a melhoria } \\
\text { da qualidade e da } \\
\text { quantidade de água. }\end{array}$ & $\begin{array}{l}\text { Capacitação em EA, voltada } \\
\text { para os recursos hídricos. }\end{array}$ \\
\hline & $\begin{array}{l}\text { Território e } \\
\text { Cultura } \\
\text { Indígenas } \\
\text { (MEC) }\end{array}$ & $\begin{array}{l}\text { Proteger a integridade } \\
\text { territorial e o patrimônio } \\
\text { cultural e ambiental das } \\
\text { sociedades indígenas }\end{array}$ & $\begin{array}{l}\text { Promoção de eventos sobre EA } \\
\text { em terras indígenas. }\end{array}$ \\
\hline
\end{tabular}

Continua... 
...continuação.

\begin{tabular}{|c|c|c|c|}
\hline Ato & Programa & $\begin{array}{c}\text { Objetivo relacionado ao } \\
\text { Programa }\end{array}$ & Ação \\
\hline \multicolumn{4}{|c|}{ 2004-2007 } \\
\hline \multirow{7}{*}{$\begin{array}{c}\text { Lei } \\
\text { no } 10.933 \text {, de } \\
11 \text { de agosto } \\
\text { de } 2004 \text {. }\end{array}$} & $\begin{array}{l}\text { Programa Brasil } \\
\text { Escolarizado } \\
\text { (MEC) }\end{array}$ & $\begin{array}{l}\text { Garantir, com melhoria de } \\
\text { qualidade, o acesso e a } \\
\text { permanência de todas as } \\
\text { crianças, os adolescentes, } \\
\text { os jovens e adultos na } \\
\text { educação básica. }\end{array}$ & $\begin{array}{l}\text { Apoio à EA nas escolas públicas } \\
\text { de educação básica. }\end{array}$ \\
\hline & \multirow{6}{*}{$\begin{array}{l}\text { Programa } \\
\text { Educação } \\
\text { Ambiental para } \\
\text { Sociedades } \\
\text { Sustentáveis } \\
\text { (MMA) }\end{array}$} & \multirow{6}{*}{$\begin{array}{l}\text { Estimular e apoiar } \\
\text { processos de EA na } \\
\text { construção de valores e } \\
\text { relações sociais, em } \\
\text { conhecimentos, } \\
\text { habilidades, atitudes e } \\
\text { competências que } \\
\text { contribuam para a } \\
\text { participação de todos na } \\
\text { edificação de sociedades } \\
\text { sustentáveis. }\end{array}$} & $\begin{array}{l}\text { a) Efetivação do Sistema } \\
\text { Brasileiro de Informação sobre } \\
\text { EA; }\end{array}$ \\
\hline & & & $\begin{array}{l}\text { b) capacitação de recursos } \\
\text { humanos para a prevenção e o } \\
\text { controle ambiental nas áreas } \\
\text { marítimas e portuárias; }\end{array}$ \\
\hline & & & $\begin{array}{l}\text { c) Educação Ambiental para } \\
\text { recursos hídricos; }\end{array}$ \\
\hline & & & $\begin{array}{l}\text { d) educação para a conservação } \\
\text { da biodiversidade; }\end{array}$ \\
\hline & & & $\begin{array}{l}\text { e) fomento a projetos integrados } \\
\text { de } E A ;\end{array}$ \\
\hline & & & $\begin{array}{l}\text { f) formação de educadores } \\
\text { ambientais. }\end{array}$ \\
\hline \multicolumn{4}{|c|}{ 2008-2011 } \\
\hline \multirow{8}{*}{$\begin{array}{l}\text { Lei } \\
\text { no } 11.653 \text {, de } \\
7 \text { de abril de } \\
2008 .\end{array}$} & \multirow{8}{*}{$\begin{array}{l}\text { Educação } \\
\text { Ambiental para } \\
\text { Sociedades } \\
\text { Sustentáveis } \\
\text { (MMA) }\end{array}$} & \multirow{8}{*}{$\begin{array}{l}\text { Construir valores e } \\
\text { relações sociais, } \\
\text { conhecimentos, } \\
\text { habilidades, atitudes e } \\
\text { competências que } \\
\text { contribuam para a } \\
\text { participação de todos na } \\
\text { edificação de sociedades } \\
\text { sustentáveis. }\end{array}$} & $\begin{array}{l}\text { a) Assistência técnica para a } \\
\text { adoção da Agenda Ambiental na } \\
\text { Administração Pública; }\end{array}$ \\
\hline & & & $\begin{array}{l}\text { b) EA para grupos em situação } \\
\text { de vulnerabilidade } \\
\text { socioambiental; }\end{array}$ \\
\hline & & & $\begin{array}{l}\text { c) educação para a conservação } \\
\text { da biodiversidade; }\end{array}$ \\
\hline & & & $\begin{array}{l}\text { d) fomento a projetos integrados } \\
\text { de } E A ;\end{array}$ \\
\hline & & & $\begin{array}{l}\text { e) formação de educadores } \\
\text { ambientais; }\end{array}$ \\
\hline & & & f) gestão compartilhada da EA; \\
\hline & & & $\begin{array}{l}\text { g) produção e difusão de } \\
\text { informação ambiental de caráter } \\
\text { educativo; }\end{array}$ \\
\hline & & & $\begin{array}{l}\text { h) publicidade de utilidade } \\
\text { pública. }\end{array}$ \\
\hline
\end{tabular}


...continuação.

\begin{tabular}{|c|c|c|c|}
\hline Ato & Programa & $\begin{array}{c}\text { Objetivo relacionado ao } \\
\text { Programa }\end{array}$ & Ação \\
\hline \multicolumn{4}{|c|}{ 2012-2015 } \\
\hline \multirow{10}{*}{$\begin{array}{l}\text { Lei no } 12.593 \\
\text { de } 18 \mathrm{de} \\
\text { janeiro de } \\
2012 .\end{array}$} & \multirow{8}{*}{$\begin{array}{l}\text { Programa de } \\
\text { Licenciamento e } \\
\text { Qualidade } \\
\text { Ambiental } \\
\text { (MMA) }\end{array}$} & \multirow{8}{*}{$\begin{array}{l}\text { Promover a EA integrada } \\
\text { às políticas e programas } \\
\text { socioambientais, } \\
\text { contribuindo para } \\
\text { construção de sociedades } \\
\text { sustentáveis. }\end{array}$} & $\begin{array}{l}\text { a) Formação de educadores } \\
\text { ambientais; }\end{array}$ \\
\hline & & & $\begin{array}{l}\text { b) produção e difusão de } \\
\text { informação ambiental de caráter } \\
\text { educativo; }\end{array}$ \\
\hline & & & $\begin{array}{l}\text { c) EA para grupos em situação } \\
\text { de vulnerabilidade } \\
\text { socioambiental; }\end{array}$ \\
\hline & & & d) gestão compartilhada da EA; \\
\hline & & & $\begin{array}{l}\text { e) incentivo a práticas culturais } \\
\text { que contribuam para } \\
\text { conservação, }\end{array}$ \\
\hline & & & consciência e EA; \\
\hline & & & $\begin{array}{l}\text { f) assistência técnica para o } \\
\text { cumprimento da Agenda } \\
\text { Ambiental na Administração } \\
\text { Pública; }\end{array}$ \\
\hline & & & $\begin{array}{l}\text { g) educação para conservação } \\
\text { da biodiversidade. }\end{array}$ \\
\hline & $\begin{array}{c}\text { Programa de } \\
\text { Licenciamento e } \\
\text { Qualidade } \\
\text { Ambiental } \\
\text { (Ministério da } \\
\text { Cultura) }\end{array}$ & $\begin{array}{l}\text { Promover EA integrada a } \\
\text { políticas e programas } \\
\text { socioambientais, } \\
\text { contribuindo para a } \\
\text { construção de sociedades } \\
\text { sustentáveis. }\end{array}$ & $\begin{array}{l}\text { Incentivo a práticas culturais que } \\
\text { contribuam para conservação, } \\
\text { consciência e EA. }\end{array}$ \\
\hline & $\begin{array}{l}\text { Conservação e } \\
\text { Uso Sustentável } \\
\text { da } \\
\text { Biodiversidade }\end{array}$ & $\begin{array}{l}\text { Promover os princípios do } \\
\text { respeito aos direitos } \\
\text { humanos, à diversidade e à } \\
\text { sustentabilidade } \\
\text { socioambiental. }\end{array}$ & $\begin{array}{l}\text { Apoio à efetivação da Política } \\
\text { Nacional de Educação (art. 2o } \\
\text { Lei no 13.005/2014). }\end{array}$ \\
\hline
\end{tabular}

Continua.. 
...continuação.

\begin{tabular}{|c|c|c|c|}
\hline Ato & Programa & $\begin{array}{c}\text { Objetivo relacionado ao } \\
\text { Programa }\end{array}$ & Ação \\
\hline \multicolumn{4}{|c|}{$2016-2019$} \\
\hline \multirow{4}{*}{$\begin{array}{c}\text { Lei } \\
\text { no } 13.249 \text {, de } \\
13 \text { de janeiro } \\
\text { de } 2016 .\end{array}$} & $\begin{array}{l}\text { Promoção dos } \\
\text { Direitos da } \\
\text { Juventude }\end{array}$ & $\begin{array}{l}\text { Promover e integrar ações } \\
\text { que contribuam para a } \\
\text { efetivação do direito da } \\
\text { juventude à } \\
\text { sustentabilidade e ao meio } \\
\text { ambiente }\end{array}$ & $\begin{array}{l}\text { Coordenação e articulação de } \\
\text { políticas públicas que promovam } \\
\text { os direitos dos jovens }\end{array}$ \\
\hline & Programa & $\begin{array}{l}\text { Ampliar o atendimento } \\
\text { escolar de qualidade em } \\
\text { todas as etapas e }\end{array}$ & $\begin{array}{l}\text { a) Adoção de ações voltadas à } \\
\text { formação inicial e } \\
\text { continuada dos profissionais } \\
\text { que atuam na Educação } \\
\text { Profissional e Tecnológica- } \\
\text { EPT; }\end{array}$ \\
\hline & $\begin{array}{l}\text { (2080): } \\
\text { Educação de } \\
\text { qualidade para } \\
\text { todos (MEC) }\end{array}$ & $\begin{array}{l}\text { modalidades da educação } \\
\text { básica (...) visando ao } \\
\text { pleno desenvolvimento da } \\
\text { pessoa, na perspectiva da } \\
\text { educação ao longo da vida } \\
\text { e à formação cidadã (...) }\end{array}$ & $\begin{array}{l}\text { b) apoio aos estudantes de } \\
\text { licenciatura para a } \\
\text { conclusão dos cursos } \\
\text { (ênfase em Física, Química, } \\
\text { Sociologia, Filosofia e } \\
\text { outras); }\end{array}$ \\
\hline & & & $\begin{array}{l}\text { c) definição de diretrizes para a } \\
\text { formação de professores de } \\
\text { EPT. }\end{array}$ \\
\hline \multicolumn{4}{|c|}{$2020-2024$} \\
\hline $\begin{array}{c}\text { Lei no } \\
13.588 \text {, de } \\
3 / 1 / 2020 \text {. }\end{array}$ & Nenhum & Nenhum & $\begin{array}{l}\text { A EA não é citada na Lei, } \\
\text { tampouco em seus anexos. }\end{array}$ \\
\hline
\end{tabular}

Fonte: Autoria própria (2020).

Uma lista de projetos e programas construídos, segundo o levantamento realizado, de maneira participativa e calcados nos princípios emanados do Tratado de 'Educação Ambiental para Sociedades Sustentáveis e Responsabilidade Global' nos anos de 2000 a 2014, com linha orçamentária nos PPAs para Formação de Educadoras e Educadores em EA pode ser citada (Quadro 3). 
Quadro 3: Lista Complementar de Ações, Metas, ou Programas, Envolvendo Formação de Educadoras e Educadores em EA.

\begin{tabular}{|c|c|c|}
\hline Ano & Projeto & $\begin{array}{l}\text { Órgão } \\
\text { Gestor }\end{array}$ \\
\hline 2008 & Viveiros Educadores. & MMA \\
\hline 2010 & Mudanças Climáticas. & MMA \\
\hline 2012 & $\begin{array}{l}\text { Programa de Educação Ambiental e Agricultura Familiar - } \\
\text { PEAAF. }\end{array}$ & MMA \\
\hline 2012 & $\begin{array}{l}\text { Projeto Com-Vida: Década da Educação para o Desenvolvimento } \\
\text { Sustentável - Implantando a Agenda } 21 \text { nas escolas (2005-2014). }\end{array}$ & MEC \\
\hline $2013-2015$ & $\begin{array}{l}\text { Plano Nacional de Juventude e Meio Ambiente - PNJMA - } \\
\text { Programa Juventude e Meio Ambiente criado em } 2003 \text { (MEC). }\end{array}$ & MEC \\
\hline 2014 & $\begin{array}{l}\text { Estratégia Nacional de Educação Ambiental (EA) e Comunicação } \\
\text { Social (CS) na Gestão de Resíduos Sólidos - EducaRES. }\end{array}$ & \\
\hline 2014 & Gerenciamento Costeiro. & MMA \\
\hline 2014 & $\begin{array}{l}\text { Plano Nacional Juventude e Meio Ambiente: Programa Nacional } \\
\text { de Acesso ao Ensino Técnico e Emprego (Pronatec -2011). }\end{array}$ & MEC \\
\hline
\end{tabular}

Fonte: Autoria própria (2020).

Observa-se, pelo histórico dos PPAs, que a Educação Ambiental, nesses vinte anos, fez parte das agendas políticas, prioritariamente, como programas finalísticos, ora sendo fortalecida no âmbito das políticas públicas educacionais e ambientais, ora em agendas transversais.

Outra constatação extraída das referências bibliográficas, objeto do presente estudo (artigos, encontros, conferências e simpósios) é o entendimento, de parte dos agentes ativos, de que a EA no Brasil deveria estar incluída no currículo escolar, para não mais ser tratada como tema transversal. Atribuem essa falha à insuficiente evolução da EA como instrumento da política de proteção ambiental brasileira, tanto no âmbito formal, quanto no não formal.

Do mesmo modo, ficou claro, durante as investigações, que os temas abordados nas publicações devem ser investigados com maior profundidade a fim de esclarecer o quanto a EA reverbera nas políticas públicas de proteção da biodiversidade; de entendimento das causalidades das mudanças climáticas; de formação de sujeitos ecológicos, entre outros temas indutores de uma consciência global mais crítica.

\section{Impressões Gerais da Educação Ambiental no Brasil}

A seguir, são sumarizadas algumas contribuições do curso de Educação Ambiental do Centro de Desenvolvimento Sustentável da Universidade de Brasília, apresentado pela Doutora Izabel Zaneti à Conferência Internacional de Educação Ambiental-CiEduca, ocorrida em 2019, na cidade de Bento Gonçalves/RS. são:

As maiores fragilidades da EA nesses vinte anos de existência da PNEA 
- dependência de ações pontuais e personalizadas;

- escassez de linhas orçamentárias crescentes ao longo do tempo, sendo totalmente ausentes no PPA 2020-2023;

- foco em atividades e datas comemorativas (Dia do Meio Ambiente, Dia da Árvore, Dia do Índio, etc.);

- ausência de abordagem crítica - inclusive no ensino superior - do nível de desempenho dos programas, planos e ações empreendidos;

- ausência de interdisciplinaridade e de transdisciplinaridade, o que inviabiliza tratamento transversal do tema EA na comunidade escolar, com foco nas questões específicas da biodiversidade e das mudanças climáticas, temas mais discutidos nacional e internacionalmente na última década;

- inexistência ou fragilidade, por vezes, da construção participativa com a comunidade escolar;

- inexistência de ações perenes de EA dentro do ambiente escolar, sendo atribuídas apenas a alguns educadores militantes da causa ambiental;

- insuficiência de capacitação para agentes da educação formal visando à abordagem crítica de EA nas escolas;

- necessidade de as instituições de pesquisa e educação superior se dedicarem a disseminar tecnologias limpas para a proteção ambiental e;

- despreparo das escolas para a definição e a assunção de parâmetros sólidos de construção participativa dos programas de EA com a comunidade escolar.

Quanto à educação não formal, listam-se:

- a permeabilização e a integração de EA na sociedade em geral têm sido, predominantemente, resultado de esforços de organizações não governamentais-ONGs ou público-privadas, como se constata em projetos de proteção ambiental: Tamar, Peixe Boi, Mico Leão Dourado, dentre outros;

- a necessidade de incentivo, a divulgação e a ampliação do voluntarismo são prementes, assim como a criação de mecanismos de retroalimentação e avaliação de desempenho das ações empreendidas;

- os projetos, afora aqueles atrelados a ONGs, carecem do 'despertar da paixão e da sensibilidade' no trato das questões de proteção ambiental; 
- os programas e ações de EA, exigidos pela PNEA no processo de Licenciamento Ambiental Federal, ainda não são aderentes às diferentes fases dos empreendimentos impactantes - planejamento, construção, operação e desativação, por isso não são os esperados instrumentos para a rastreabilidade de uma maior consciência crítica no que tange ao desenvolvimento econômico e sustentabilidade ambiental;

- a fiscalização e o acompanhamento dos programas de EA pelos órgãos ambientais licenciadores, durante o ciclo de vida dos empreendimentos licenciados, é muito incipiente, sendo, seus resultados significantes apenas no planejamento (licença prévia), e nas fases restantes parte de relatórios não divulgados e nem garantidores de sua eficácia como instrumento de proteção ambiental.

Finalmente, é notório o distanciamento entre os tomadores de decisão e os professores, pesquisadores, agentes de mobilização social e as práticas da PNEA no Brasil. É imprescindível que todas e todos sejam, urgentemente, capacitados e sensibilizados para a promoção da EA como instrumento de sustentabilidade em todos os níveis de ensino e de exercício profissional.

\section{Situação Atual da PNEA}

Como dito anteriormente, em 2018, quando da elaboração do PPA 20202023 (aprovado em 10 de dezembro de 2019 e promulgado por meio da Lei no 13.971, de 27 de dezembro de 2019), o tema da EA foi totalmente omitido. A EA não possui qualquer citação no corpo da Lei, tampouco em seus anexos. Assim, a precariedade do ensino da disciplina deverá se agravar por falta de recursos.

Quanto ao Programa de Conservação e Uso Sustentável da Biodiversidade e dos Recursos Naturais, caberia ao MMA a "'Implementação' de Ações de Cidadania e Educação Ambiental" e, ao Instituto Brasileiro do Meio Ambiente e dos Recursos Naturais Renováveis-Ibama, o "Monitoramento Ambiental e Gestão da Informação sobre o Meio Ambiente e Educação Ambiental".

Todavia, tais ações não mais integram a agenda de EA. Deixaram de ser tratadas como Políticas Públicas e Programas (BRASIL, 2019), pois foram relegadas a segundo plano, com sua transferência, pelo governo atual, à Secretaria de Ecoturismo, vinculada ao Ministério de Turismo.

Com o esvaziamento político-institucional da agenda de EA no âmbito dos órgãos gestores da PNEA - MMA e MEC - muitos desafios serão impostos a essa temática, cuja agenda "se mostra cada vez mais importante nos processos de conservação da natureza e de construção da sustentabilidade" (REDE BRASILEIRA DE EDUCAÇÃO AMBIENTAL, 2019). 
De maneira geral, até 2014, quando teve início uma forte crise institucional em razão do processo de impeachment da então Presidenta Dilma Rousseff e da consequente assunção do vice-presidente, Michel Temer, houve uma mudança político-institucional no Poder Executivo, mudanças que se refletiram nas pastas da Educação e do Meio Ambiente.

Desde então, conforme demonstrado nos Quadros 1 e 2, as execuções das políticas públicas de EA - planos, ações e projetos públicos - arrefeceram, reduzindo-se, assim, os resultados práticos dos programas que ainda estavam em vigência.

Para complicar ainda mais o quadro de arrefecimento da discussão e da aplicação da PNEA, no governo atual (2019-2022), vislumbra-se uma forte descontinuidade provocada pela extinção da Coordenação-Geral de Educação Ambiental-CGEA e do Departamento de Educação Ambiental-DEA, órgãos responsáveis pela gestão da PNEA no MEC e no MMA, respectivamente.

O DEA/MMA compartilhava as quatro diretrizes traçadas pelo MMA, no sentido de transversalizar o estímulo e o apoio à construção de sociedades sustentáveis, promovendo controle e a participação social em todos os setores da sociedade brasileira, por meio do fortalecimento do Sisnama.

No âmbito do MEC, a EA foi atrelada à CGEA, subordinada à Diretoria de Políticas e Regulação da Educação Básica da Secretaria de Educação Básica, a qual compete ('ia'), dentre outras, "orientar e fomentar, [...] desenvolvimento de políticas, programas e ações para a educação integral, a Educação Ambiental e os temas transversais" (BRASIL, 2019).

Recentemente, por meio do Decreto Federal no 9.672, de 2 de janeiro de 2019, que aprova a Estrutura Regimental e o Quadro Demonstrativo dos Cargos e Comissões do MMA, determinou-se, em seu artigo 28, que, dentre as atribuições da Secretaria de Ecoturismo, ficaria o apoio "à coordenação $e$ definição de políticas públicas relacionadas à promoção geral de atividades, campanhas, eventos e articulações de conscientização ambiental, relacionamento e interação com influenciadores, relacionados ao ecoturismo". E no seu artigo 31, coube ao Departamento de Fomento e Projetos "(...) realizar e planejar projetos e ações de fomento a Ecoeconomia, Educação Ambiental e Ecoturismo e nos diversos segmentos e entes federativos, bem como nos meios influenciadores", e (...) "acompanhar e monitorar ações, iniciativas, estratégias, programas e projetos de Ecoeconomia, Educação Ambiental e Ecoturismo" (grifos nossos).

Várias organizações da sociedade civil saíram em defesa da Educação Ambiental: a Rede Brasileira de Educação Ambiental - Rebea; o Fórum Brasileiro de Ongs e Movimentos Sociais-FBOMS; o Fórum Nacional da Sociedade Civil em Comitês de Bacias Hidrográficas-Fonasc; a Confederação Nacional dos Trabalhadores na Educação-CNTE, além de pesquisadores, professores, membros da comunidade científica brasileira. 
Em carta aberta aos gestores do MMA e MEC, tais organizações assim se manifestaram (...):

(...) a Educação Ambiental perde sua maior marca, qual seja, a de articulação institucional e de formação ampla na área ambiental, incluindo todos os níveis e modalidades de ensino, bem como as diversas instâncias não escolarizadas da sociedade em geral (para além do ecoturismo apenas), divergindo assim do que prevê a Lei da Política Nacional de Educação Ambiental". (...) Por sua vez, ao colocar a Educação Ambiental em uma Secretaria exclusiva do ensino básico, por mais importante e necessário que seja, desconsidera-se preceito legal que diz que no caso da educação formal, a Educação Ambiental deve ocorrer desde a educação infantil até o ensino superior (REDE BRASILEIRA DE EDUCAÇÃO AMBIENTAL, 2019).

Entretanto, é neste cenário, neste campo de lutas, em que a cultura da descontinuidade política e administrativa de programas/planos, de "Autoritária opressão simbólica sobre aqueles que pensam diferente dos que estão no núcleo do poder", tão presentes na lógica do Estado brasileiro, que se deve repensar o papel dos coletivos/redes de EA e reverberar para dentro deste campo, debates e diálogos voltados a ultrapassar toda predeterminação e naturalização que envolve discurso político-ambiental que vem se instalando no País (LAYRARGUES, 2010).

Como bem enfatizou Layrargues (op. cit.), em circunstâncias não tão análogas, é nos "projetos societários que representam para o país, para a questão ambiental que devemos neste momento colocar em foco as discussões". Se se quer uma Educação Ambiental que vise a desenvolver uma "consciência crítica acerca das instituições, atores e fatores sociais geradores de riscos e respectivos conflitos socioambientais" é imperativo, "discutir, compartilhar ou refutar as ideias" e construir pontes sobre o abismo que ora se avizinha (LAYRARGUES, 2002, op. cit.; CARVALHO, 2010).

\section{Conclusões}

O status dos planos e projetos aqui apresentados demonstra que a EA, nessas duas décadas, mesmo com críticas subjacentes ao quadro geral constatado, repercutiu em diferentes espaços coletivos. Essas conquistas, oriundas "de anos de interação entre educadores ambientais, especialistas, sociedade civil organizada e órgãos públicos ambientais e educacionais", além de órgãos privados, demostram que novas racionalidades foram delineadas, que novos "laços identitários" foram construídos e que o empoderamento dos grupos sociais foi fortalecido (REDE BRASILEIRA DE EDUCAÇÃO AMBIENTAL, 2019).

revista brasileira educação ambiental 
Que é preciso avançar, todos já sabem, mas qual será a estratégia? Talvez não exista, neste momento, uma estratégia que possa romper o ostracismo em que foi lançada a PNEA a partir dessas reformulações políticoadministrativas do governo federal. É mister observar como tais reformulações repercutirão nos diferentes entes da federação, posto que devem, por mandado constitucional, estar alinhados à política da União. E é inegável que uma estratégia urgente seja redesenhada e discutida para combater 0 desmantelamento da EA no Brasil em face dessas políticas e a falta de recursos financeiros delas decorrente.

O Estado deveria, segundo a PNEA, assumir o estímulo, o subsídio e o certificado de parcerias entre instituições oficiais com objetivo precípuo de formar educadores ou agentes que possam assumir tal função, pois é o único modo de garantir um processo continuado de formação de educadores ambientais.

Com a atual ordenação político-administrativa do governo federal, sobram dúvidas sobre o nível do comprometimento e da capilaridade das ações do OG com os coletivos educadores, que vinham subsidiando parcerias e o desenvolvimento das ações de EA no País.

Por fim, uma questão importante que permanece subjacente é que a Educação Ambiental deve ser regulada com o objetivo claro de ser popular, crítica e emancipatória. Independentemente de o governo federal pactuar com esse princípio, urge que se constitua um conjunto social articulado, que não permita o abandono de ações que subsidiem essa perspectiva mandatória. Às políticas públicas em EA, dessa forma, resta preconizar, de maneira urgente e sensível, um processo dialético e partilhado entre Estado e sociedade.

\section{Agradecimentos}

Ao Centro de Desenvolvimento Sustentável da Universidade de Brasília, em especial aos alunos da disciplina de Educação Ambiental do segundo semestre de 2019, por agregarem comentários ao presente artigo.

\section{Referências}

BARBOSA, L. C. Políticas públicas de Educação Ambiental numa sociedade de risco: Tendências e desafios no Brasil. Anais do IV Encontro Nacional da Anppas. 4 a 6 de junho. 2008. 21 p.

BRASIL. Ministério do Meio Ambiente. Secretaria de Articulação Institucional e Cidadania Ambiental. Departamento de Educação Ambiental. Coletivos Educadores para Territórios Sustentáveis. Brasília: MMA, 2007. Disponível em: https://www.mma.gov.br/estruturas/educamb/ arquivos/cartilha coleds.pdf. Acesso em: 11 nov. 2019. 
BRASIL. Ministério do Meio Ambiente. Conferência Nacional Infantojuvenil pelo Meio Ambiente: Primeira Década de Uma História. Brasília, DF: MMA, 2018a. Disponível em: https://www.mma.gov.br/publicacoes/educacaoambiental/category/199-conferenciainfantojuvenil.html?download=1450:caderno primeira d\%C3\%A9cada de um a hist\%C3\%B3ria. Acesso em: 7 de fev. 2020.

BRASIL. [Constituição (1988)]. Constituição da República Federativa do Brasil de 1988. Brasília, DF: Presidência da República, [2016]. Disponível em: http://www.planalto.gov.br/ccivil 03/constituicao/constituicao.htm. Acesso em: 20 out. 2019.

BRASIL. Ministério do Meio Ambiente. Educação Ambiental por um Brasil Sustentável: Pronea, Marcos Legais e Normativos. Brasília, DF: MMA, 2018b. Disponível em: https://www.mma.gov.br/publicacoes/educacaoambiental/category/98-Pronea.html?download=1580:programa-nacional-deeduca\%C3\%A7\%C3\%A3o-ambiental-5\%C2\%AA-edi\%C3\%A7\%C3\%A30. Acesso em: 11 nov. 2019.

BRASIL. Decreto $n^{\circ}$ 9.665, de 2 de janeiro de 2019. Aprova a Estrutura Regimental e o Quadro Demonstrativo dos Cargos em Comissão e das Funções de Confiança do Ministério da Educação, remaneja cargos em comissão e funções de confiança e transforma cargos em comissão do GrupoDireção e Assessoramento Superiores - DAS e Funções Comissionadas do Poder Executivo - FCPE. Brasília, DF: Presidência da República, [2019]. Disponível em: http://www.planalto.gov.br/ccivil 03/ Ato20192022/2019/Decreto/D9665.htm. Acesso em: 20 out. 2019.

BRASIL. Lei $n^{\circ} 6.938$, de 31 de agosto de 1981. Dispõe sobre a Política Nacional do Meio Ambiente, seus fins e mecanismos de formulação e aplicação, e dá outras providências. Brasília, DF: Presidência da República, [2015]. Disponível em: http://www.planalto.gov.br/ccivil 03/LEIS/L6938.htm. Acesso em: 20 out. 2019.

BRASIL. Lei $n^{\circ} 9.795$, de 27 de abril de 1999. Dispõe sobre a educação ambiental, institui a Política Nacional de Educação Ambiental e dá outras providências. Brasília, DF: Presidência da República, [1999]. Disponível em: http://www.planalto.gov.br/ccivil 03/leis/19795.htm. Acesso em: 20 out. 2019 .

BRASIL. Ministério do Meio Ambiente. Ministério da Educação. Programa Nacional de Educação ambiental - ProNEA. 3를 ed. Brasília, DF: MMA, 2005. Disponível

em: https://www.mma.gov.br/estruturas/educamb/ arquivos/pronea3.pdf.

Acesso em: 6 fev. 2020.

CARVALHO, I.C.M. Nomes e endereços da Educação Ambiental. VI Fórum Brasileiro de Educação Ambiental: Participação, Cidadania e Educação Ambiental. Niterói: Instituto Baía de Guanabara, 2010. p.39-46. Disponível 
em: http://www.imasul.ms.gov.br/wp-content/uploads/2016/03/Livro-VIF\%C3\%B3rum-vers\%C3\%A3o-final.pdf. Acesso em: 11 nov. 2019.

CASTELLS, M. A Sociedade Em Rede: a Era da Informação, Economia, Sociedade e Cultura. Ed. Paz e Terra. 2008. 698 p.

LAYRARGUES; P.P. A crise ambiental e suas implicações na educação. In: QUINTAS, J.S. (org.). Pensando e praticando a Educação Ambiental na gestão do meio ambiente. $2^{\mathrm{a}}$ ed. Brasília: Ibama, p. 161-198. 2002.

LOUREIRO, C.F.B. Educar, participar e transformar em educação ambiental. In: Revista Brasileira de Educação Ambiental - $n^{\circ} 0$ (nov. 2004). Brasília, DF: Rede Brasileira de Educação Ambiental, 2004. 140 p. Disponível em: $\langle$ http://assets. wwfbr.panda.org/downloads/revbea n zero.pdf\#page $=13>$. Acesso em: 2 jan. 2020.

MORAIS, J.L.; VIEIRA, E.R.; MORTELLA, R.D. Os desafios da Conferência Nacional Infantojuvenil pelo Meio Ambiente: percepções dos participantes das Comissões Organizadoras Estaduais. REMEA - Revista Eletrônica do Mestrado em Educação Ambiental, [S.I.], p. 49-62, nov. 2018. ISSN 1517-1256. Disponível em: https://periodicos.furg.br/remea/article/view/8562. Acesso em: 7 de fev. 2020.

REDE BRASILEIRA DE EDUCAÇÃO AMBIENTAL. Nota da REBEA aos Senhores Ministros da Educação e do Meio Ambiente. 2019. Disponível em: http://www.reasul.org.br/index.php/14-triade/destaques/1085-nota-da-

REBEA-aos-senhores-ministros-da-educacao-e-do-meio-ambiente. Acesso em: 29 dez. 2019.

SECCHI, L. Políticas públicas: Conceitos, esquemas de análise, casos práticos. $2^{\mathrm{a}}$ ed. São Paulo: Cengage Learning, 2014.

SOUZA, C. Políticas públicas: uma revisão da literatura. Sociologias, Porto Alegre, 8(16): 20-45. 2006.

SPINAK, E. Google Acadêmico, Web of Science ou Scopus, qual nos dá melhor cobertura de indexação? [online]. SciELO em Perspectiva, Disponível em: <https://blog.scielo.org/blog/2019/11/27/google-academico-web-of-scienceou-scopus-qual-nos-da-melhor-cobertura-de-indexacao/>. 2019. Acesso em 18 janeiro de 2020.

TRAJBER, R.; MENDONÇA, P. R. (orgs). Educação na diversidade: o que fazem as escolas que dizem que fazem Educação Ambiental. Brasília: Secretaria de Educação Continuada, Alfabetização e Diversidade, 2007. Coleção Educação para Todos, Série Avaliação; 6 (23). 2007. 